\title{
Low-density lipoprotein receptor expression is involved in the beneficial effect of photodynamic therapy using talaporfin sodium on gastric cancer cells
}

\author{
TSUTOMU KANDA ${ }^{1}$, TAKAAKI SUGIHARA ${ }^{1}$, TOMOAKI TAKATA ${ }^{1}$, YUKARI MAE ${ }^{1}$, HIDEHITO KINOSHITA ${ }^{1}$, \\ TAKUKI SAKAGUCHI ${ }^{1}$, TAKASHI HASEGAWA ${ }^{1}$, HIROKI KURUMI $^{1}$, YUICHIRO IKEBUCHI ${ }^{1}$, \\ TAKASHI MURAKAMI ${ }^{2}$ and HAJIME ISOMOTO ${ }^{1}$ \\ ${ }^{1}$ Division of Medicine and Clinical Science, Faculty of Medicine Tottori University, Yonago, Tottori 683-8504; \\ ${ }^{2}$ Department of Microbiology, Faculty of Medicine Saitama Medical University, Moroyama, Saitama 350-0495, Japan
}

Received June 29, 2018; Accepted January 17, 2019

DOI: $10.3892 / \mathrm{ol} .2019 .10004$

\begin{abstract}
Photodynamic therapy (PDT) is a therapeutic method used to destroy tumor tissue via reactive oxygen. Notably, reactive oxygen is induced by a combination of photosensitizers, including talaporfin sodium (TS) and laser light. Gastric cancer cell lines, MKN45 and MKN74, were used to evaluate the effect of TS-PDT in vitro. The antitumor effect of TS-PDT, which was evaluated via cellular viability assay, on MKN74 was weaker than that on MKN45 cells, suggesting that MKN74 cell could be resistant to TS-PDT. However, using a higher TS concentration or setting a longer treatment time ( $24 \mathrm{~h}$ ) resulted in effective TS-PDT treatment on MKN74 cells. In addition, when irradiation power of LED was raised up to $5.06 \mathrm{~J} / \mathrm{cm}^{2}$, TS-PDT was able to induce an antitumor effect on MKN74 cells. This suggested that the difference in TS-PDT efficacy between MKN45 and MKN74 cells is based on the difference in cellular uptake of TS. As expected, uptake of TS by MKN74 cells was lower than that by MKN45 cells. The expression levels of low-density lipoprotein (LDL) receptor in MKN74 cells were lower than those in MKN45 cells. With GW3965 treatment, an agonist/activator of Liver X Receptor, LDL receptor expression was reduced, weakening the TS-PDT effect. Furthermore, as a hydroxymethylglutaryl-Coenzyme A reductase inhibitor, treatment using simvastatin increased LDL receptor expression, leading to enhancement of the TS-PDT effect on MKN74 cells. In conclusion, the difference in LDL receptor expression between the two gastric cell lines could influence TS-PDT efficacy; simvastatin may enhance
\end{abstract}

Correspondence to: Professor Hajime Isomoto, Division of Medicine and Clinical Science, Faculty of Medicine Tottori University, 36-1 Nishi-cho, Yonago, Tottori 683-8504, Japan

E-mail: isomoto@med.tottori-u.ac.jp

Key words: talaporfin sodium, photodynamic therapy, low-density lipoprotein receptor, simvastatin, gastric cancer cell lines the antitumor effect of TS-PDT through upregulating the LDL receptor even on PDT-resistant gastric cancer cells.

\section{Introduction}

Photodynamic therapy (PDT) is a minimally invasive treatment with fewer side effects (1). PDT is known to be effective on many types of cancers including esophageal and gastric cancer (2). Early gastric cancer with a nominal risk of metastatic malignancy can be cured by local treatment such as endoscopic resections, including endoscopic submucosal dissection (ESD) (3) or PDT (2). Compared to endoscopic resections, PDT controls technical quality more easily. However, PDT using the first-generation photosensitizer, porfimer sodium, and excimer dye laser has several problems such as a high occurrence of skin phototoxicity, a long sun shade period and the necessity of an expensive and large laser system for excitation (2). In contrast, the second-generation photosensitizer, talaporfin sodium (TS) is rapidly cleared from the skin, requiring shorter sun shade period. Furthermore, the antitumor effect can be deeper through the submucosal layer even to the muscularis propria because the excited wavelength of diode laser is longer $(664 \mathrm{~nm})$ than excimer dye laser (630 nm). Recently, Yano et al successfully performed a phase II study to evaluate the efficacy and safety of TS-PDT using a diode laser for local failure after chemoradiotherapy (CRT) or radiotherapy (RT) alone, against esophageal cancer (4). In 2015, TS-PDT was approved by Ministry of Health, Labour and Welfare (MHLW) in Japan for this indication setting. In addition, it has been already adapted for brain glioblastoma and lung cancer; however, TS-PDT has not been approved for gastric cancer by MHLW despite its medical needs.

Matsumoto et al established an experimental system to evaluate antitumor effect of TS-PDT for biliary tract cancer cells in vitro, and reported that TS-PDT induced rather high tumor necrosis and apoptosis; it also inhibited cellular proliferation efficiently (5). However, TS-PDT effect has not been evaluated in gastric cancer cells in vitro.

In this study, we used the above established in vitro system to evaluate the antitumor effect of TS-PDT on gastric cancer 
cells, MKN45 and MKN74. As there were differences of the antitumor effect between these two cell lines, we assessed the underlying mechanisms especially in the viewpoint of low-density lipoprotein (LDL) receptor mediated-uptake of TS. Since porphyrins have high affinity to the LDL receptor (6), TS could be bound by the LDL receptor as well.

Furthermore, we used GW3965 and simvastatin to evaluate the effect of LDL receptor expression. GW3965 is agonist/activator of Liver X Receptor (LXR) which inhibits the LDL receptor pathway through transcriptional induction of inducible degrader of the LDL receptor $(7,8)$. Simvastatin is an HMG-CoA (hydroxymethylglutaryl-Coenzyme A) reductase inhibitor, which is a therapeutic agent for hypercholesterolemia by virtue of enhancing the expression of LDL receptor and absorbing blood cholesterol (9).

\section{Materials and methods}

Human gastric cancer cell lines and cultures. MKN45-Luc and MKN74/CMV-Luc cells were obtained from JCRB cell bank. Cells were grown in RPIM-1640 medium supplemented with $10 \%$ fetal bovine serum and $1 \%$ L-glutamine solution without antibiotics. The cells were cultured in a humidified incubator with $5 \% \mathrm{CO}_{2}$ at $37^{\circ} \mathrm{C}$.

Reagents. TS, GW3965 (10054) and simvastatin (196-17801) were purchased from Meiji Seika Pharma Co., Ltd. (Tokyo, Japan), Cayman Chemical Co. (Ann Arbor, Michigan, USA), and Fujifilm Wako Pure Chemical Co., Ltd. (Osaka, Japan), respectively. Rabbit monoclonal anti-LDL-receptor antibody (ab52818; Abcam PLC, Tokyo, Japan), rabbit monoclonal anti- $\beta$-actin (D6A8) antibody (8457; CST Japan Co., Ltd., Tokyo, Japan) and horseradish peroxidase (HRP)-conjugated goat anti-Rabbit IgG H\&L (ab97051; Abcam PLC) were purchased for western blotting analysis.

Microscopic imaging. Cells were visualized under a fluorescent microscope (BZ-X710; Keyence Co., Osaka, Japan) with the filters included BZ-X filter GFP and for TS (OP-87763 and OP-87767; Keyence Co.). The latter has excitation filter (405BP20) and fluorescence filter (RPE630LP). The software BZ-analyzer (Keyence Co.) was used for merging, reducing noise and enhancing the signal intensity.

PDT protocol and proliferation assay. Cells were treated with GW3965 and simvastatin reagent for $22 \mathrm{~h}$ as this is the earliest time at which the effect can be observed and cultured for $4 \mathrm{~h}$ with TS in serum-free medium, $660 \mathrm{~nm}$ light (LEDR-660DL; Optocode Co., Ltd., Tokyo, Japan) was irradiated at $2.53 \mathrm{~J} / \mathrm{cm}^{2}(5)$ and cell viability was measured by MTS (3-(4,5-dimethylthiazol-2-yl)-5-(3-carboxymethoxy-phenyl)-2-(4-sulfophenyl)-2H-tetrazolium) assay. We usually evaluate the effect of TS-PDT $24 \mathrm{~h}$ after LED irradiation, but for simvastatin, the effect was clearly observed $48 \mathrm{~h}$ after LED irradiation. MTS Assay was performed as below; $20 \mu \mathrm{l}$ proliferation assay solution (G3580, CellTiter $96^{\circledR}$ AQueous One Solution Cell Proliferation Assay; Promega Co., Tokyo, Japan) added to $100 \mu \mathrm{l}$ culture medium, and after an hour, absorbance of $490 \mathrm{~nm}$ was measured by microplate reader (Vientonano; DS Pharma Biochemical Co., Ltd.,
Osaka, Japan). Finally, we calculated the viability against control cell.

Fluorescent staining of intracellular organelle. Cells were treated by lysosome staining reagent (C10507, CellLight ${ }^{\mathrm{TM}}$ Lysosome-GFP, BacMam 2.0; Thermo Fisher Scientific, Inc.). This reagent is a fusion constructed with lysosomal associated membrane protein 1 and emGFP, providing specific targeting to cellular lysosomes, and is packaged in the insect virus baculovirus. We added this reagent to cells, incubated the cells overnight, and then observed GFP-tagged lysosomes in the cells using a fluorescent microscopy and a standard GFP filter set. We observed that TS had a porphyrin structure showing fluorescence, and emitted red light at $630 \mathrm{~nm}$ when excitation light irradiation was at $405 \mathrm{~nm}$.

Western blotting analysis. Cultured cells were directly lysed for $15 \mathrm{~min}$ on ice with RIPA Lysis and Extraction Buffer (89900; Thermo Fisher Scientific Inc., Tokyo, Japan) containing with cOmplete ${ }^{\mathrm{TM}}$ ULTRA Tablets, Mini, EASYpack Protease Inhibitor Cocktail and PhoSTOP (05892970001 and 4906845001; Roche Diagnostics Co., Ltd., Tokyo, Japan). After centrifugation at $21,500 \mathrm{x}$ g for $15 \mathrm{~min}$, protein concentrations were measured using Pierce $660 \mathrm{~nm}$ Protein Assay Reagent (1861426; Thermo Fisher Scientific, Inc.), and protein was denatured by boiling for $5 \mathrm{~min}$. Equal weights of protein $(40 \mu \mathrm{g})$ protein was loaded onto sodium dodecyl sulfate-polyacrylamide gels for electrophoresis and then transferred onto nitrocellulose membranes. After blocking with 5\% milk in TBST (150 mmol/l $\mathrm{NaCl}$ and $50 \mathrm{mmol} / \mathrm{l}$ Tris- $\mathrm{HCl}$ containing $0.05 \%$ Tween-20), the membranes were incubated with anti-LDL receptor antibody (dilution, 1:1,000) and anti- $\beta$-Actin antibody (dilution, 1:1,000) at $4^{\circ} \mathrm{C}$ overnight. After washing with TBST 3 times $(5 \mathrm{~min}$ each), the membranes were incubated with their corresponding HRP-conjugated secondary antibodies (dilution, 1:5,000) at room temperature for $1 \mathrm{~h}$. After washing with TBST 3 times (5 min each), bound antibodies were visualized using Clarity Western ECL Substrate (1705061; Bio-Rad Laboratories, Inc., Tokyo, Japan) and image analyzer (LAS-3000 mini; Fujifilm Co. Ltd., Tokyo, Japan).

RNA extraction. Total RNA from cultured cells was extracted using miRNeasy Mini Kit (217004; Qiagen Co., Ltd., Tokyo, Japan). The RNA was quantified using a NanoDrop 1000 spectrophotometer (Thermo Fisher Scientific, Inc.). Extracted RNA samples were stored at $-80^{\circ} \mathrm{C}$ until used.

Reverse transcription-quantitative polymerase chain reaction (RT-qPCR). cDNAs were prepared from total RNA using High-Capacity cDNA Reverse Transcription Kit (4374966; Thermo Fisher Scientific,Inc.). The RT reactions were performed in aliquots containing 2,000 ng of total RNA, 1X RT buffer, $4 \mathrm{mM}$ dNTP mix, 1X RT random primer, 50 units multiscribe reverse transcriptase, 20 units RNase inhibitor, and nuclease-free water added up to $20 \mu \mathrm{l}$ at $25^{\circ} \mathrm{C}$ for $10 \mathrm{~min}$, followed by $37^{\circ} \mathrm{C}$ for $120 \mathrm{~min}$ and $85^{\circ} \mathrm{C}$ for $5 \mathrm{~min}$. Primer sequences for quantitative PCR are below, LDL receptor forward, CCCGACCCC TACCCACTT and reverse, AATAACACAAATGCCAAA TGTACACA; and $\beta$-actin forward, GCATCCTCACCCTGA AGTA and reverse, TGTGGTGCCAGATTTTCTCC. qPCR 

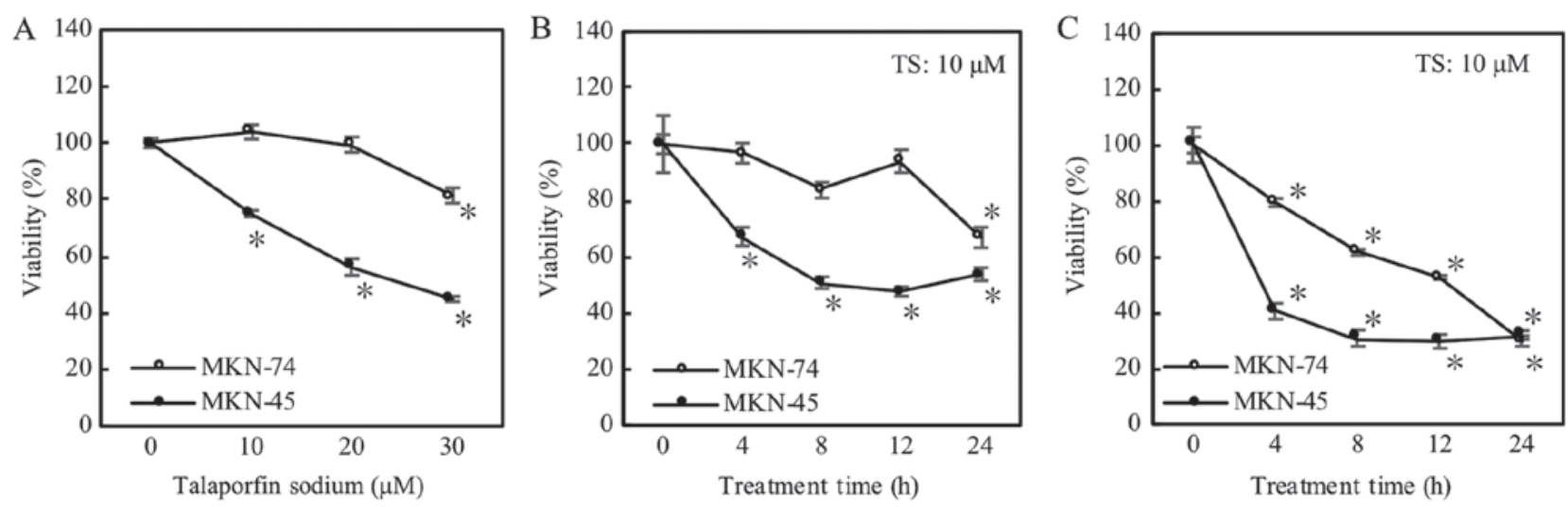

Figure 1. Photodynamic therapy evaluation via proliferation assay. Cell viability was measured at 1 day after LED. * $<0.05$ vs. each control ( $\mathrm{n}=4$ ). Error bar is expressed as standard error. (A) Treatment time at $4 \mathrm{~h}$ with LED power at $2.53 \mathrm{~J} / \mathrm{cm}^{2}$. (B) Concentration of TS was $10 \mu \mathrm{M}$ and LED power was $2.53 \mathrm{~J} / \mathrm{cm}^{2}$. (C) Concentration of TS was $10 \mu \mathrm{M}$ and irradiation power of LED was $5.06 \mathrm{~J} / \mathrm{cm}^{2}$. TS, talaporfin sodium.

reaction was performed in $20 \mu \mathrm{l}$ aliquots containing $1 \mu \mathrm{l} \mathrm{RT}$ products with $4 \mu \mathrm{l}$ LightCycler ${ }^{\circledR}$ FastStart DNA MasterPLUS SYBR-Green I (03515869001; Roche Diagnostics Co., Ltd.), $0.5 \mu \mathrm{M}$ each primer and $14.6 \mu 1$ nuclease-free water and run on the Real-Time PCR Lightcycler 1.5 Complete System (Roche Diagnostics Co., Ltd.). Thermal cycling was initiated with a first denaturation step at $95^{\circ} \mathrm{C}$ for $10 \mathrm{~min}$, followed by 45 cycles of $95^{\circ} \mathrm{C}$ for $10 \mathrm{sec}, 60^{\circ} \mathrm{C}, 10 \mathrm{sec}$ and $72^{\circ} \mathrm{C}, 10 \mathrm{sec}$. The cycle passing threshold $\left(\mathrm{C}_{t}\right)$ was recorded for mRNA by LightCycler Software version 3.5.28 (Roche Diagnostics Co., Ltd.) and $\beta$-actin was used as the endogenous control for data normalization. Relative expression was calculated using the formula $2^{-\Delta \Delta \mathrm{Ct}}=2^{-(\Delta \mathrm{Ct} \text {, reagent treatment- } \Delta \mathrm{Ct} \text {, control })}(10)$.

Statistical analysis. The differences between groups were analyzed using the paired, two-tailed, Student's t-test. The differences among three groups were analyzed using one-way analysis of variance followed by Tukey's post hoc test. Data were expressed as means \pm standard error. Differences were considered statistically significant at $\mathrm{P}<0.05$.

\section{Results}

Differences of PDT efficacy between MKN-45 and MKN-74 cells. As shown in Fig. 1A, the effect of TS-PDT at $2.53 \mathrm{~J} / \mathrm{cm}^{2}$ on MKN74 cells was less than on MKN45; cellular viabilities were not decreased within $20 \mu \mathrm{M}$ of TS concentration. Using higher concentration $(30 \mu \mathrm{M})$ of TS, MKN74 cells showed enhancement of the effect (Fig. 1A). In the longest treatment time of $24 \mathrm{~h}$ at $10 \mu \mathrm{M}$ of TS, cellular viability was decreased significantly (Fig. 1B). In addition, when irradiation power of LED raised up to $5.06 \mathrm{~J} / \mathrm{cm}^{2}$ at $10 \mu \mathrm{M}$ of TS, TS-PDT induced the decrease in cellular viabilities even on MKN74 cells (Fig. 1C). In summary, MKN74 cells seemed rather resistant to TS-PDT compared to MKN45 cells.

$L D L$ receptor is associated with uptake of TS. As shown with longer treatment time with TS, the difference in the effects between MKN45 and MKN74 cells could be due to the ability of cellular uptake of TS. Considering the correspondence of location and their mergence in color, similar to LDL intracellular movement (11), TS was carried into the lysosome (Fig. 2A).
In fact, uptake of TS in MKN74 cells at $4 \mathrm{~h}$ was lower than MKN45 cells at this particular time-point (Fig. 2B). The uptake tended to be increased at the time-point of $24 \mathrm{~h}$. In addition, we confirmed that the expression levels of LDL receptor protein and mRNA in MKN74 cells were lower than MKN45 cells, respectively (Fig. 2C and D).

Decreased LDL receptor by GW3965 induces PDT-resistant. Furthermore, we used GW3965 to confirm whether LDL receptor could be related to uptake of TS. As expected, LDL receptor expression was reduced by GW3965 treatment as shown in Fig. 3A. Subsequently, GW3965 treatment significantly increased cellular viabilities on MKN45 cells (from 10 to $30 \mu \mathrm{M}$ concentration of TS) and MKN74 cells at $30 \mu \mathrm{M}$ TS (Fig. 3B and C).

Increased $L D L$ receptor by simvastatin enhances efficacy of $P D T$. When these cells were treated with simvastatin at $20 \mu \mathrm{M}$, both protein and mRNA expression levels of LDL receptor were substantially increased (Fig. 4A and B, respectively). Simvastatin significantly decreased cellular viabilities, and enhanced the PDT effects, on MKN74 cells (Fig. 4D). On the other hand, simvastatin did not affect cellular viabilities on MKN45 cells as shown in Fig. 4C.

\section{Discussion}

In this paper, we elucidated that LDL receptor expression is involved in the effect with TS-PDT, and simvastatin enhances the therapeutic effect on TS-PDT resistant cell.

PDT has been shown to be a safe and effective treatment for early gastric cancer, not only for the intramucosal type, but also for the submucosal invasion. PDT using the excimer-dye laser and Photofrin ${ }^{\circledR}$ (porfimer sodium, the first-generation photosensitizer) can be an endoscopic treatment option for gastric cancer particularly in a rapidly aging society like Japan (2). In clinical practice, PDT is administered at $40 \mathrm{mg} / \mathrm{m}^{2}$ of TS per person and $100 \mathrm{~J} / \mathrm{cm}^{2}$ of laser light. This concentration is similar to that in in vitro conditions. However, the LED power is different. This is because we need to eradicate cancer cells in clinical practice completely, but need fewer effective conditions for evaluating reagents in vitro. In addition, cells are 
A

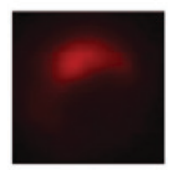

Talaporfin

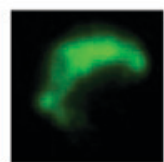

Lysosome

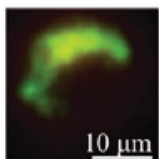

Merged

B

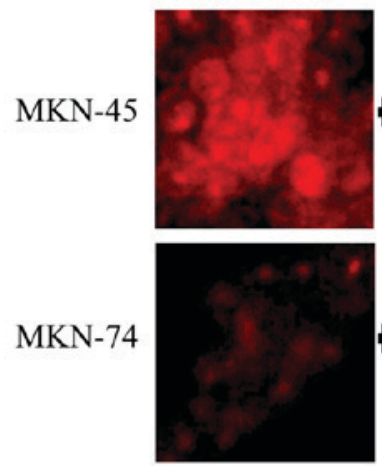

$4 \mathrm{~h}$
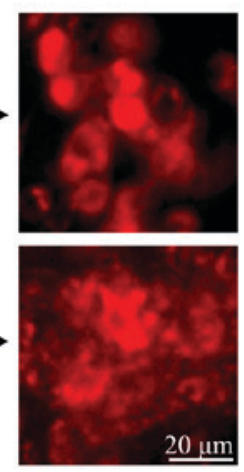

$24 \mathrm{~h}$
$\mathrm{C}$

LDL-R

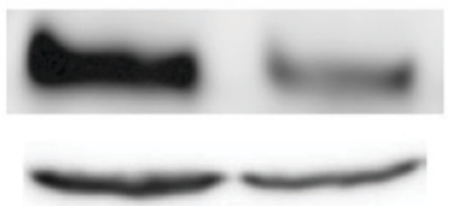

MKN-45 MKN-74

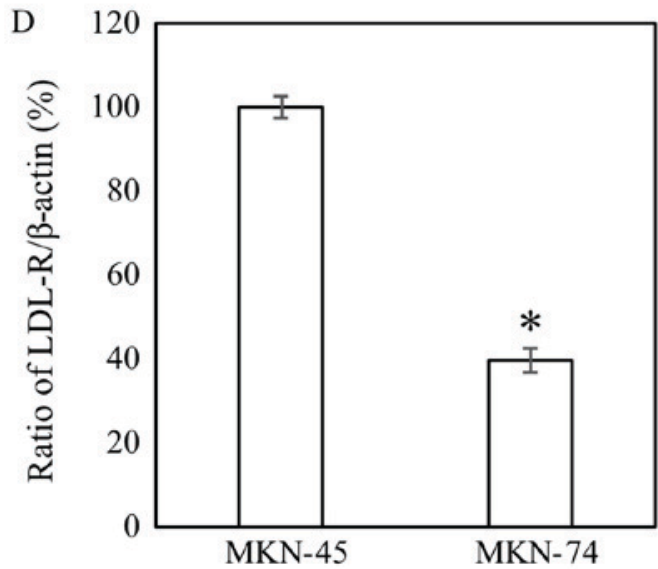

Figure 2. Talaporfin sodium uptake and LDL receptor expression. (A and B) Lysosome was stained green and TS was red (Objective lens, $\mathrm{x} 10)$. (C and D) LDL receptor expression by western blotting and reverse transcription-quantitative polymerase chain reaction. ${ }^{*} \mathrm{P}<0.05$ vs. $\mathrm{MKN}-45$ ( $\mathrm{n}=3$ ). Error bar is expressed as standard error. LDL, low-density lipoprotein; TS, talaporfin sodium.

A

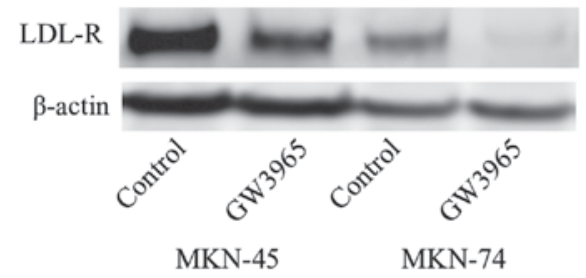

B

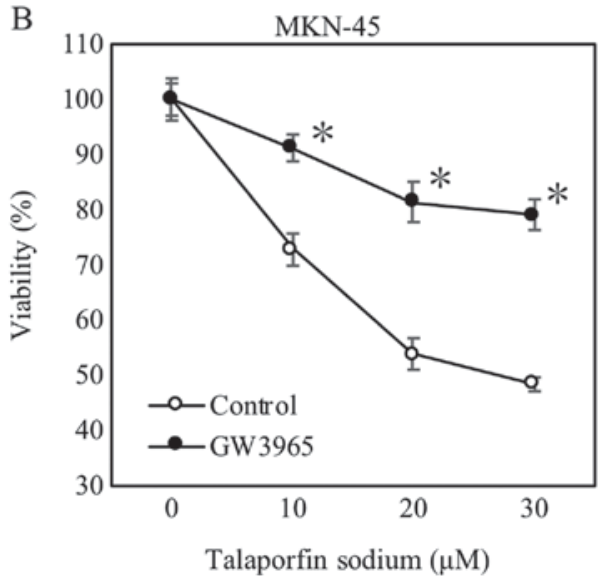

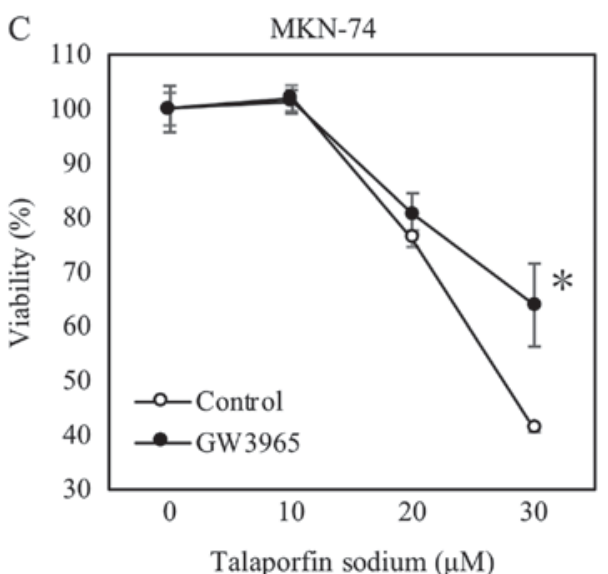

Figure 3. Determination of GW3965 effect on LDL receptor expression and proliferation. Concentration of GW3965 was $2 \mu \mathrm{M}$. Each asterisk was expressed as significant indicator. (A) LDL receptor expression determined by western blotting. (B and C) Cell viability is measured at one day after LED. * P<0.05 vs. each control $(n=4)$. Error bar is expressed as standard error. LDL, low-density lipoprotein.

cultured in a monolayer fashion in vitro. Therefore, we think that we need less LED power in in vitro system compared to that in clinical practice.

As PDT using TS on gastric cancer is yet to be approved by MHLW in Japan, and currently is not available in clinical settings, therefore we investigated the effects of TS-PDT on gastric cancer cell. In the present study, MKN74 cells were shown to be resistant to TS-PDT. There were substantial differences in expression levels of LDL receptor between MKN74 cells and TS-PDT-sensitive MKN45 cells. TS was localized in the lysosome possibly after being taken by LDL receptor. Downregulation of LDL receptor by GW3965 significantly decreased the effect of TS-PDT in gastric cancer cells. Furthermore, LDL receptor expression was decreased by 
A
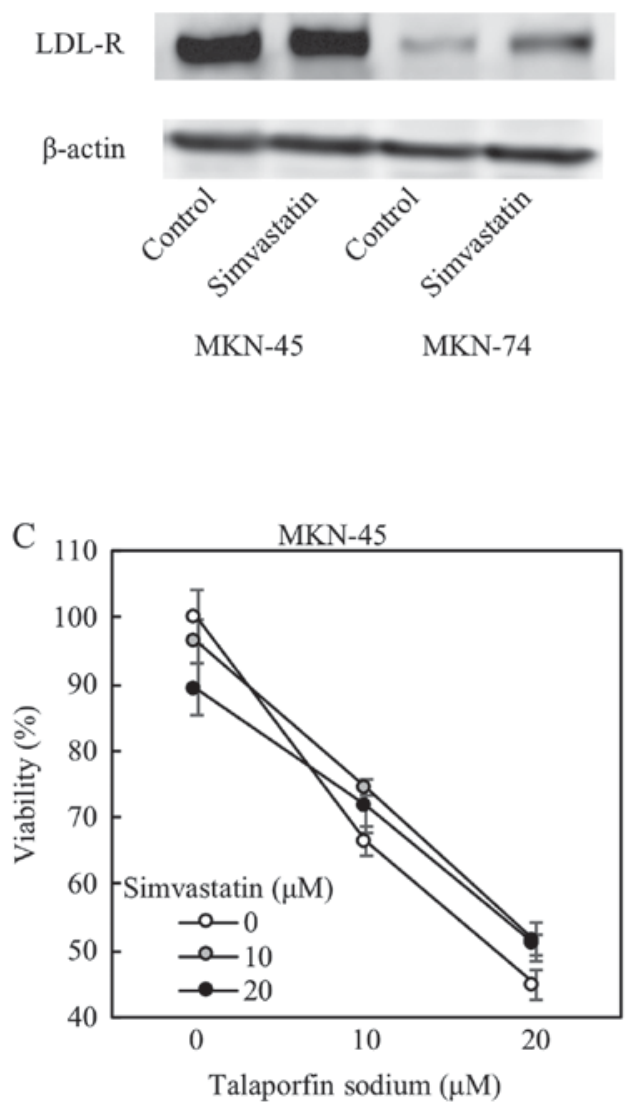
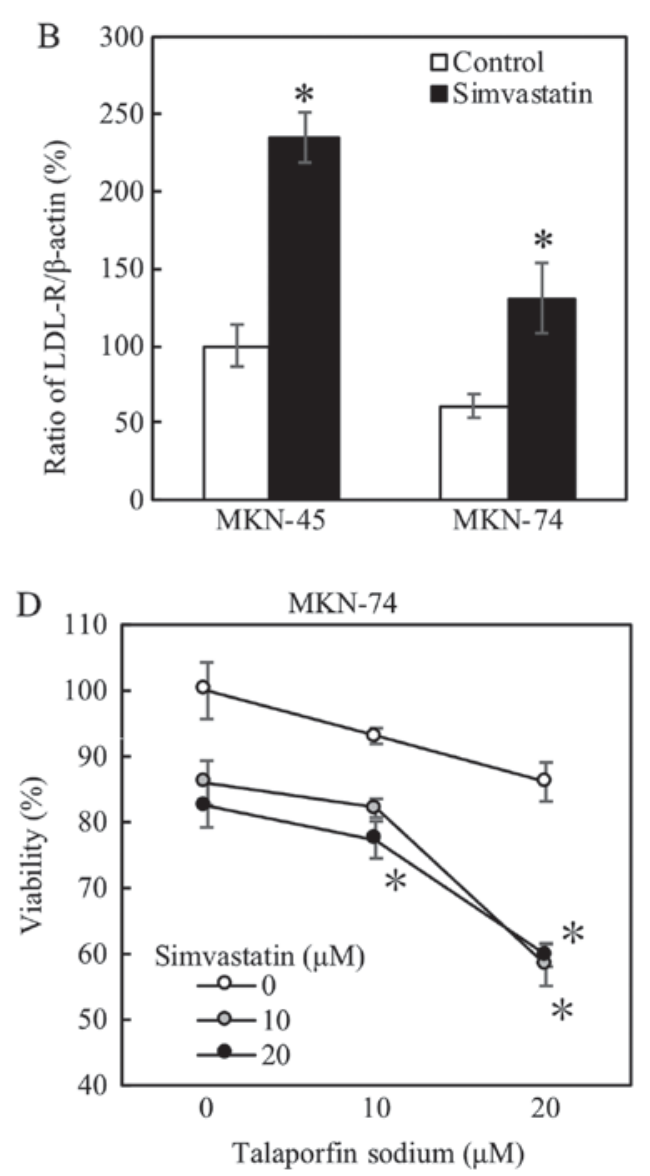

Figure 4. Simvastatin effect evaluated by LDL receptor expression and by proliferation assay. Concentration of simvastatin is $20 \mu \mathrm{M}$. Each asterisk was expressed as significant indicator. Error bar is expressed as standard error. (A) and (B) LDL receptor expression by western blotting and quantitative PCR. ${ }^{*} \mathrm{P}<0.05$ vs. control ( $\mathrm{n}=3$ ). (C) and (D) Cell viability is measured at two days after LED. * $\mathrm{P}<0.05$ vs. control ( $\left.\mathrm{n}=4\right)$. LDL, low-density lipoprotein.

siRNA knockdown (Fig. S1). The viability was increased from $52.0 \pm 6.25$ to $56.8 \pm 5.11 \%$ for MKN45 cells $(n=6)$. We were able to observe an up-trend of viability although not statistically significant while LDL receptor expression was decreased by siRNA. The effect of GW3965 might have been caused by other molecules and receptor contributing to the resistance. On the other hand, simvastatin-mediated LDL receptor upregulation enhanced the effect of PDT in MKN74 cells but not in MKN45 cells, in which LDL receptor could be sufficiently expressed. Therefore, the difference of LDL receptor expression between these two gastric cell lines could affect TS-PDT efficacy.

In our experiments, simvastatin did not have such a dramatic effect on TS-PDT low-sensitive MKN74 cells. Firstly, in regard of the uptake of TS, there could be expressing several other receptors including albumin receptor (12) and heme-carrier protein-1 (13) in addition to LDL receptor (6). Although LDL receptor could be used for uptake of TS in the gastric cancers, upregulation by simvastatin gave just the partial effect of TS-PDT. Secondly, recent research documented that simvastatin itself has an antitumor effect (14), therefore, we did not use higher concentration of simvastatin. In contrast, simvastatin at moderately higher concentrations decreased the viability of MKN74 cells in the TS-PDT in vitro model (Fig. 4D). However, by adding simvastatin to TS-PDT in an in vitro system, we could observe that TS-PDT was effective even on resistant cells. The viability (60\%) was close to the equivalent with TS-PDT sensitive cell (50\%). This datum shows the possibility of combining TS-PDT and simvastatin in clinical practice. Under the criteria of approval by Japanese Universal Health Insurance Coverage System, the efficacy of PDT with Photofrin ${ }^{\circledR}$ for gastric cancer with superficial early gastric cancer was good, with 42 patients $(73.7 \%)$ out of 57 patients (70 lesions) showed a complete response (Fulfills both 1 and 2). i) No residual tumor at the original lesion examined endoscopically. ii) Biopsy specimen shows no carcinoma cells) (2). In the resistant residual or remnant cases despite PDT treatments, simvastatin or similar derivatives might show enhanced/additive effects of PDT, paving the way for novel combination therapy.

On the other hand, remaining cancer stem cells could cause a relapse after anticancer drugs and radiation therapy (15). In fact, TS-PDT was rather effective for local failure after CRT or RT alone against superficially localized esophageal cancer (16). TS-PDT might be rather effective for aggressive gastric cancer with cancer stem cell appearance, considering the origin of these cell lines; MKN45 cell line was derived from undifferentiated-type gastric cancer, whereas MKN74 cell line was established from differentiated-type gastric cancer. ESD is currently in widespread use for early gastric cancer (17). However, when tumors invade the submucosa or have potential risks of metastatic malignancy, additional therapies including surgery would be necessary following ESD (18). With a rapidly aging population in Japan, additional 
surgical intervention is still debatable in particular for elderly patients with high risk comorbidities, suggesting an urgent need for a safer and more efficient therapy in gastric cancer. Therefore, further studies are necessary to evaluate underlying mechanisms of PDT with TS.

In conclusion, LDL receptor expression is involved in the efficacy of TS-PDT. Therefore, simvastatin has the possibility to enhance the effects of TS-PDT as a novel combination therapy.

\section{Acknowledgements}

Not applicable.

\section{Funding}

No funding was received.

\section{Availability of data and materials}

All data generated or analyzed during this study are included in this published article.

\section{Authors' contributions}

TK and TSu acquired data, analyzed and interpreted the data, and drafted the manuscript. TT also analyzed and interpreted the data. YM, HKi, TSa, TH and HKu assisted in acquiring the data. YI made contributions to the conception and design of the study. TM established MKN45-Luc and MKN74/CMV-Luc cells. HI made substantial contributions to the conception and design of the study and drafted the manuscript.

\section{Ethics approval and consent to participate}

Not applicable.

\section{Patient consent for publication}

Not applicable.

\section{Competing interests}

The authors declare that they have no competing interests.

\section{References}

1. Shafirstein G, Bellnier D, Oakley E, Hamilton S, Potasek M, Beeson K and Parilov E: Interstitial photodynamic therapy-a focused review. Cancers (Basel) 9: pii: E12, 2017.

2. Oinuma T, Nakamura T and Nishiwaki Y: Report on the National survey of photodynamic therapy (PDT) for gastric cancer in Japan (a secondary publication). Laser Ther 25: 87-98, 2016.

3. Isomoto H, Shikuwa S, Yamaguchi N, Fukuda E, Ikeda K, Nishiyama H, Ohnita K, Mizuta Y, Shiozawa J and Kohno S: Endoscopic submucosal dissection for early gastric cancer: A large-scale feasibility study. Gut 58: 331-336, 2009.
4. Yano T, Kasai H, Horimatsu T, Yoshimura K, Teramukai S, Morita S, Tada H, Yamamoto Y, Kataoka H, Kakushima N, et al: A multicenter phase II study of salvage photodynamic therapy using talaporfin sodium (ME2906) and a diode laser (PNL6405EPG) for local failure after chemoradiotherapy or radiotherapy for esophageal cancer. Oncotarget 8: 22135-22144, 2017.

5. Matsumoto J, Suzuki K, Yasuda M, Yamaguchi Y, Hishikawa Y, Imamura $\mathrm{N}$ and Nanashima A: Photodynamic therapy of human biliary cancer cell line using combination of phosphorus porphyrins and light emitting diode. Bioorg Med Chem 25: 6536-6541, 2017.

6. Shibata Y, Matsumura A, Yoshida F, Yamamoto T, Nakai K, Nose T, Sakata I and Nakajima S: Competitive uptake of porphyrin and LDL via the LDL receptor in glioma cell lines: Flow cytometric analysis. Cancer Lett 166: 79-87, 2001.

7. Gabbi C, Warner M and Gustafsson JÅ: Action mechanisms of liver X receptors. Biochem Biophys Res Commun 446: 647-650, 2014.

8. Zelcer N, Hong C, Boyadjian R and Tontonoz P: LXR regulates cholesterol uptake through idol-dependent ubiquitination of the LDL receptor. Science 325: 100-104, 2009.

9. Bard JM, Luc G, Douste-Blazy P, Drouin P, Ziegler O, Jacotot B, Dachet C, De Gennes JL and Fruchart JC: Effect of simvastatin on plasma lipids, apolipoproteins and lipoprotein particles in patients with primary hypercholesterolaemia. Eur J Clin Pharmacol 37: 545-550, 1989.

10. Livak KJ and Schmittgen TD: Analysis of relative gene expression data using real-time quantitative PCR and the 2(-Delta Delta C(T)) method. Methods 25: 402-408, 2001.

11. Underwood KW, Jacobs NL, Howley A and Liscum L: Evidence for a cholesterol transport pathway from lysosomes to endoplasmic reticulum that is independent of the plasma membrane. J Biol Chem 273: 4266-4274, 1998.

12. Ogawa E, Motohashi S, Ito A and Arai T: Effects of albumin binding on photocytotoxicity of extracellular photosensitization reaction using talaporfin sodium to rat myocardial cells. Photodiagnosis Photodyn Ther 12: 252-257, 2015.

13. Cho MR, Han JH, Lee HJ, Park YK and Kang MH: Mitochondrial reactive oxygen species accelerate the expression of heme carrier protein 1 and enhance photodynamic cancer therapy effect. J Clin Biochem Nutr 56: 49-56, 2015.

14. Pavan LM, Rêgo DF, Elias ST, De Luca Canto G and Guerra EN: In vitro antitumor effects of statins on head and neck squamous cell carcinoma: A systematic review. PLoS One 10: e0130476, 2015.

15. Dragu DL, Necula LG, Bleotu C, Diaconu CC and ChivuEconomescu M: Therapies targeting cancer stem cells: Current trends and future challenges. World J Stem Cells 7: 1185-1201, 2015.

16. Nagai K, Muto M, Ezoe Y, Yamamoto T, Niimi M, Yoshimura K, Yoda Y, Yano T, Higashino K, Iishi H, et al: A phase I study of salvage photodynamic therapy (PDT) using talaporfin sodium and a diode laser for local failure of esophageal carcinoma (EC) after chemoradiotheapy (CRT). J Clin Oncol 1: 1-7, 2012.

17. Iizuka T, Kikuchi D, Hoteya S, Kajiyama Y and Kaise M: Efficacy and safety of endoscopic submucosal dissection for superficial cancer of the cervical esophagus. Endosc Int Open 5: E736-E741, 2017.

18. Ikeda A, Hoshi N, Yoshizaki T, Fujishima Y, Ishida T, Morita Y, Ejima Y, Toyonaga T, Kakechi Y, Yokosaki H and Azuma T: Endoscopic submucosal dissection (ESD) with additional therapy for superficial esophageal cancer with submucosal invasion. Intern Med 54: 2803-2813, 2015.

This work is licensed under a Creative Commons Attribution-NonCommercial-NoDerivatives 4.0 International (CC BY-NC-ND 4.0) License. 